\title{
Efficient and Flexible Technology for Binder Roving Manufacturing
}

\author{
Jens Mack* and Peter Mitschang \\ Manufacturing science, Institut fuer Verbundwerkstoffe GmbH, Kaiserslautern, Germany \\ * Corresponding author. E-mail: jens.mack83@gmail.com \\ Received: 30 January 2015; Accepted: 31 March 2015; Published online: 22 April 2015 \\ (C) 2015 King Mongkut's University of Technology North Bangkok. All Rights Reserved.
}

\begin{abstract}
Liquid Composite Molding (LCM) processes are state of the art for the manufacturing of Fiber Reinforced Polymer Composites (FRPC). In the present paper a newly developed method for the manufacturing of binder rovings is defined. The binder roving consists of heavy tow carbon fibers combined with thermoset binder material. Different manufacturing units, such as the binder conveying system or the binder application system, were developed and optimized regarding the distribution quality and the output rate. For all tests a 50k SGL roving and a Huntsman XB 3366 binder material were used as input material.
\end{abstract}

Keywords: Processing technologies, Preforming, Binder, Roving

\section{Introduction}

Preforming is a key element for the automated manufacturing of "Fiber Reinforced Polymer Composites" (FRPC) in LCM processes. Thus, it is nowadays requested from the aeronautic sector and more and more also from the automotive and mechanical engineering industry. The replacement of metallic parts by FRPCs based on semi-finished textiles (e.g. fabrics, non-woven fabrics) is state of the art. Due to the structure of the reinforcements, these components do not show optimal weight reduction, and therefore a load-optimized fiber orientation is required. This can be reached by reducing the amount of textile layers by adding unidirectional (UD) rovings in load direction to FRCP's which leads to a higher performance / weight relation. The "Dry Fiber Placement" technology can be used to place UD binder rovings for load optimization on top of a textile or fabric preform. Within a following Liquid Composite Molding process the preform is saturated with resin to get the final FRPC part. There are only a few suppliers of binder rovings on the market and the selection in terms of different fiber types and binder polymers is poor. Also, the existing products and the technology for manufacturing is expensive compared to the raw fibers and binder particles, which limits strongly the potential of this technology. To solve these limitations a new binder manufacturing method was developed and is described in this paper.

\section{State of the Art}

Preforms can be manufactured from nearly all kinds of fibers in order to get a near net-shaped reinforcement, ready for infiltration with a resin system. Preforming is one step of the LCM process chain in which a dry preform is infiltrated with liquid resin. Various LCM processes and their special issues and fields of applications are described in the literature [1]. For all of them an automated preliminary preforming process bears a huge potential for efficiency increase.

In the following the common preforming processes are described in detail. The preforming processes can be subdivided into two main categories which are shown in Figure 1. In direct processes the preform

Please cite this article as: J. Mack and P. Mitschang, "Efficient and Flexible Technology for Binder Roving Manufacturing," KMUTNB Int J Appl Sci Technol, Vol. 8, No. 2, pp. 93-100, Apr.-June 2015, http://dx.doi.org/10.14416/j.ijast.2015.03.002 


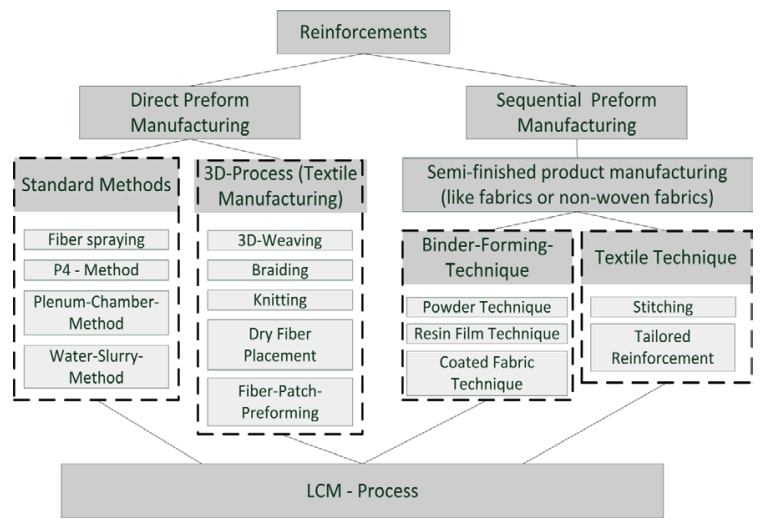

Figure 1: Preforming classification [2].

is directly manufactured from fibers. The category is further subdivided into "Standard Methods" and "3D Processes". The sequential preform processes draw back on semi-finished textile products and the category can be further subdivided into binder- and textile techniques. This paper focuses on a direct preforming process.

In the literature several examples of direct preforming methods are illustrated. Three of them "Tailored Fiber Placement", "Fiber-Patch-Preforming", and "Dry Fiber Placement" are described below. The Tailored Fiber Placement and the Dry Fiber Placement are actually the most common techniques, whereas the Fiber-Patch-Preforming is a promising research approach. With all these methods a basic preform can be locally optimized to reduce weight and costs.

The preforms manufacturing process "Tailored Fiber Placement" (TFP) base on the stitching technology. TFP was developed at IPF (Institut für Polymerforschung e.V. Dresden, Germany). An additional UD reinforcement can be fixated in any direction on a semi-finished textile product, such as a woven, non-woven fabric or a mat [3,4]. The basic material should carry the general loads without stress peaks [5]. Additional loads can be carried with the fixed roving material. During the fiber placement a small amount of endless fibers (fiber materials such as carbon, glass or aramid are possible) are fixed to the basic material. Alternatively, the number of fibers can be increased (for example $24 \mathrm{k}$ instead of $12 \mathrm{k}$ ). The reinforcement rovings are fixed to the basic part in a more or less elliptical cross-sectional geometry.
If the number of fibers increases, the possibility of a resin rich zone between the fibers rises. Also the undulation at crossing places have a higher negative effect [6]. With this technology net-shape accuracy as well as the performance of a reinforced part can be increased, especially if local imperfections like fixing holes are reinforced $[4,7]$.

Another load optimized preform manufacturing method is the "Fiber-Patch-Preforming" (FPP). This technology uses binder coated rovings as reinforcement. The reinforcements are cut into so called "patches" with a defined length of $40-65 \mathrm{~mm}$ and round or rectangular end geometry. A pick and place robot system transfers the cut patches to the preform and places them on top of the preform. With a separate end-effector the binder particles on the surface are activated (heating \& pressure application) and the patch is fixed on the preform [8-10]. With the FPP technology it is possible to manufacture reinforced parts with complex geometries. The main disadvantage of the technology is the limited output rate. This leads to a strong restriction concerning the size and the quantity of the manufactured parts. Also the lack of handling and quality measurement systems prevents the actual usage of this technology in mass production.

The "Dry Fiber Placement" (DFP) uses precoated binder rovings within a tape placement process [11]. Binder particles are available as thermoplastic or thermoset material. Three different strategies are possible to apply the binder material on or in a roving: powder, liquid (Hot-melt) or mesh. With DFP it is possible to manufacture preforms, which consist only of UD-rovings as well as the local optimization of crimp or non-crimp fabric $[12,13]$. The Dry Fiber Placement process can also be combined with the above described TFP process [14] or with a fiber spraying process [15-18].

One main disadvantage is that the possibility of variation of the purchased binder roving is limited. Customer changes are mostly possible only for longterm planned activities and only for high volume orders or for a high price addition.

The main target of this paper is to present a novel manufacturing method for the binder roving manufacturing to improve the disposability and the possible variations of binder rovings. Within this new process some disadvantages of the "Dry-FiberPlacement" process could be solved, which are listed 
in Table 1. The developed hardware is ready to be implemented into an "In-Situ Dry Fiber Placement" process, which means the direct binder application during the lay-up.

Table 1: Dry-Fiber-Placement vs. In-Situ Binder Roving Placement

\begin{tabular}{|c|c|}
\hline \multicolumn{1}{|c|}{ Dry-Fiber-Placement } & In-situ Dry-Fiber-Placement \\
\hline $\begin{array}{l}\text { - Fiber and binder material } \\
\text { selection is limited and defined } \\
\text { from the supplier }\end{array}$ & $\begin{array}{l}\text { + Free material choice } \\
\text { (binder and fiber) }\end{array}$ \\
\hline In case of an In-situ Binder Roving Placement (not part of the paper) \\
\hline $\begin{array}{l}\text { - Constant and predefined } \\
\text { binder content }\end{array}$ & $\begin{array}{l}\text { + Adjustable binder content } \\
\text { during the placement }\end{array}$ \\
\hline - Constant binder roving width & $\begin{array}{l}\text { + Adjustable roving width } \\
\text { during the placement }\end{array}$ \\
\hline
\end{tabular}

\section{Materials}

For this parameter study a carbon fiber from SGL (SGL Sigrafil 50k C030, 3300 tex) was selected as binder roving reinforcement. The relevant material data is summarized in Table 2.

Table 2: Material data Sigrafil C030

\begin{tabular}{|c|c|c|c|c|}
\hline 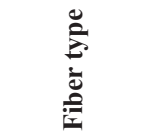 & 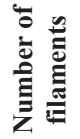 & 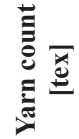 & 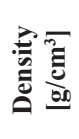 & 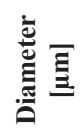 \\
\hline $\begin{array}{l}\text { Sigrafil } \\
\text { C030 Basic } \\
\text { modulus }\end{array}$ & $50 \mathrm{k}$ & 3300 & 1,80 & 7 \\
\hline 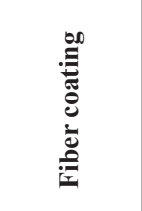 & 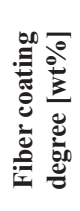 & 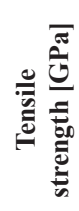 & 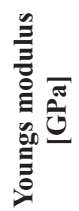 & 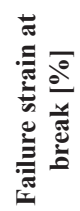 \\
\hline Epoxy & 1,0 & 4,0 & 240 & 1,7 \\
\hline
\end{tabular}

One of the most crucial issues for a reliable preform manufacturing is the quality of the input materials. A consistent binder application is useless, if the titer of a roving shows a high variation. In this case the measured binder content (weight) will also

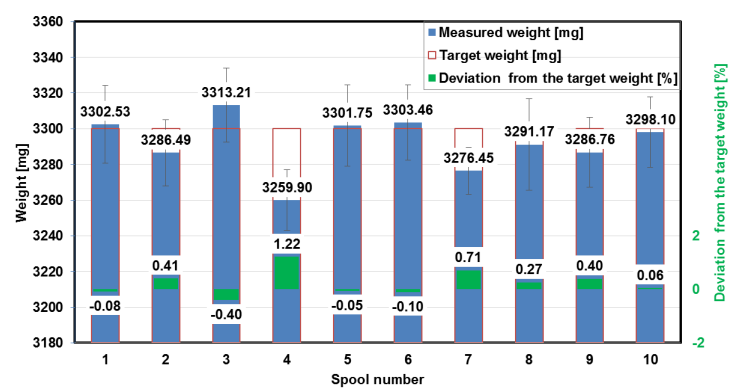

Figure 2: SGL 50k weight analysis for different spools.

strongly vary. To prevent this, the input weight per meter (tex) of each roving spool was analyzed. In Figure 2 the roving titer (tex) of different spools of the SIGRAFIL C030 is shown. For each spool 20 samples were analyzed with a XPE205 balance from Mettler Toledo, Switzerland. After unpacking the spools the first $50 \mathrm{~m}$ roving were wound up to ensure a homogeneous material quality without any packaging influences. The roving titer was measured for 20 samples of each $1 \mathrm{~m}$ length. The red bars represent the deviation from the target. Both material spools with the highest deviation ( 0.71 and $1.22 \%)$ were not be used for the measurements.

A bisphenol-a based powder binder (XB 3366) from Huntsman Advanced Materials, Switzerland was used. The material data is figured out in Table 3.

Table 3: Material data Huntsman XB 3366

\begin{tabular}{|c|c|c|c|}
\hline $\begin{array}{c}\text { Epoxy index } \\
{[\mathbf{E q} / \mathbf{k g}]}\end{array}$ & $\begin{array}{c}\text { Hydroxyl value } \\
{[\mathbf{E q} / \mathbf{k g}]}\end{array}$ & $\begin{array}{c}\text { Density at } \mathbf{2 5}^{\circ} \mathbf{C} \\
{\left[\mathbf{g} / \mathbf{c m}^{3}\right]}\end{array}$ & $\begin{array}{c}\text { Flash point } \\
{\left[{ }^{\circ} \mathbf{C}\right]}\end{array}$ \\
\hline $0.34-0.42$ & 3.1 & $1.17-1.19$ & $\geq 215$ \\
\hline
\end{tabular}

The size of the powder (XB3366) was analyzed with a "Vibratory Sieve Shaker ANALYSETTE 3 PRO" from FRITSCH, Germany. For the analysis, different sieves were stacked on each other. The binder was filled in the top sieve (largest gap width $500 \mu \mathrm{m}$ ). Due to a vibration of the system the binder particles were separated in each sieve (five sieves). All binder particles which were smaller than the smallest sieve (gap width of $25 \mu \mathrm{m}$ ) are stored in a catch container.

In dependence on the known weight of the incoming binder, the percentage of binder in each sieve could be calculated. The results of the particle size analysis are shown in Figure 3. 


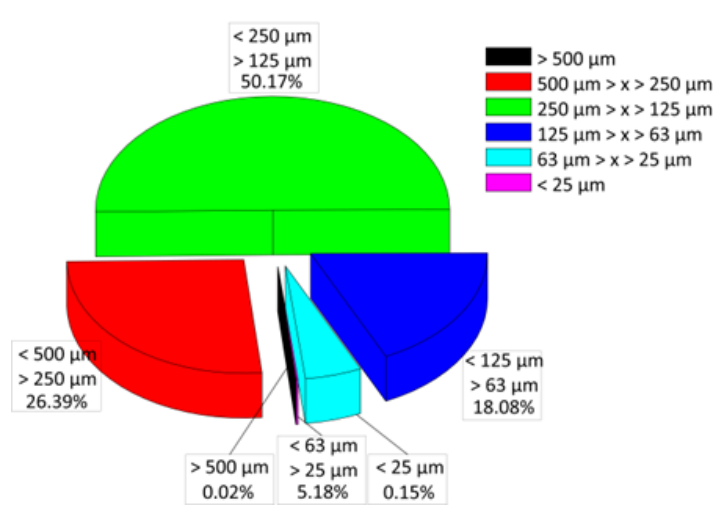

Figure 3: Powder particle size distribution - Huntsman XB3366.

\section{Process Description for the Binder Roving Manufacturing}

Binder rovings consist of a standard reinforcement roving and a thermoplastic or thermoset polymer. During the manufacturing of binder rovings the binder needs to be applied on a reinforcement roving.

For the newly developed process, all manufacturing steps from the roving to the final binder preform are shown in Figure 4.

During the first step "rewinding" the input carbon fiber material is slidly spread and rewound, that the fibers are lying upon each other without a cross winding path. The roving on a standard bobbin (width of $12-16 \mathrm{~mm}$ ) are wound up with a cross winding design, which could lead to twists at each angle change (left and right side of the bobbin). With a defined alignment of rods the roving can be supported without twists to the spreading unit. Inside the spreading unit the roving is spread due to deflections of rods. Depending on the deflection angle and the radius of the rods the roving width is adjustable. After the spreading unit the roving (width $25-30 \mathrm{~mm}$ ) is rewound with a paper interlayer. The interlayers prevent an interlocking of the spread fibers during the next processing step.

After this preparation the binder application process can start. For this a Binder-Tap-Rig (B-T-R) was developed (shown in Figure 5). The material spool with interlayers is mounted on the test rig. Within a spreading unit the width of the roving is adjusted to a predefined value (in this case $20 \mathrm{~mm}$ ). A contact free measurement system detects the roving width before the binder is applied.

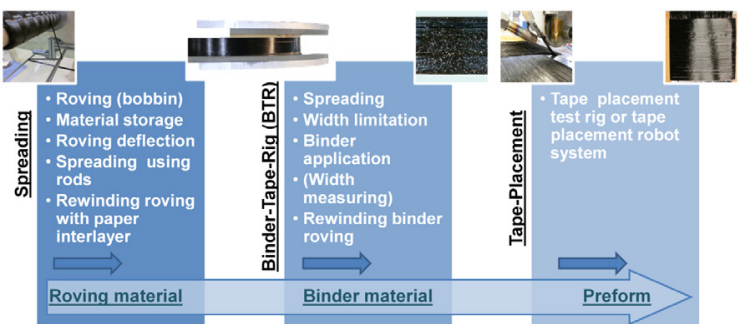

Figure 4: Manufacturing steps (roving to preform).

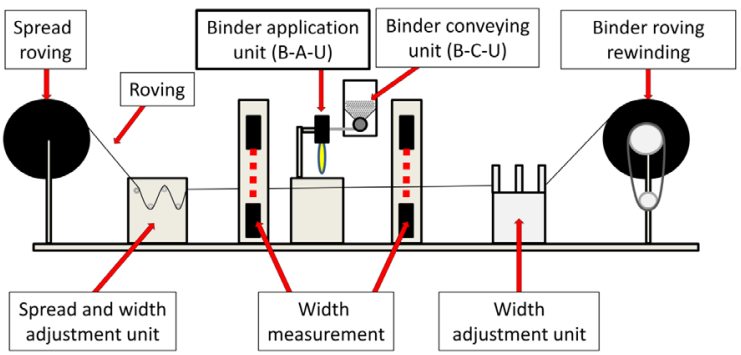

Figure 5: Binder application process.

The roving in the Binder-Application-Unit (B-A-U) consists of the binder deposition and fixation by heating. To measure the width of the roving after the B-A-U an additional measurement system is installed. After cooling of the binder (below the melting point) a second width adjustment unit reduces the binder roving to $13 \mathrm{~mm}$. Subsequently, the binder roving is rewound on a standard spool (Häfner BSH 315). The offline binder roving production is finished and the binder roving can be used in a Dry Fiber Placement process. In principle all developed units are ready to be directly mounted to the tape placement head for the "In-Situ Dry-Fiber-Placement".

\section{Results}

The complete binder application process (Figure 5) is subdivided into several units, within the BinderConveying-Unit (B-C-U) is the most critical unit. The following parameters should be achievable with the B-C-U:

- Conveying of powder binder (thermoplastic and thermoset)

- Binder conveying directly in an air flow

- Variation of the bindercontent from 1-10 mass \% depending on the processed reinforcement (tex) 


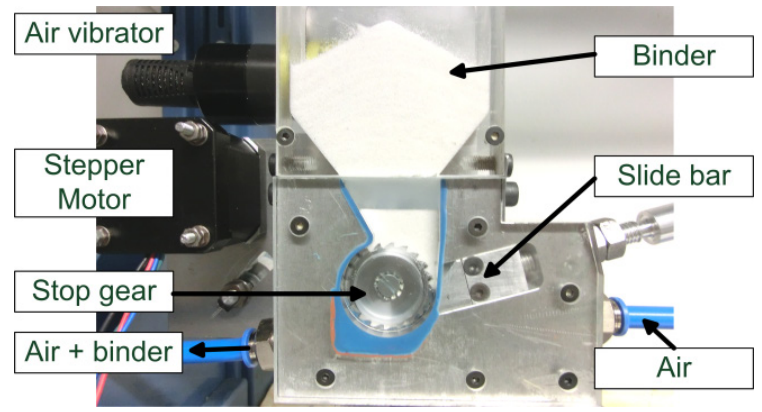

Figure 6: Binder-Conveying-Unit.

During the development of the B-C-U three different conveying systems were tested. The first binder conveying system was based on an extruder, the second on a gear conveying system and the third on a low pressure conveying system. After an evaluation and test step the gear conveying system was selected for manufacturing. Both other systems were cancelled for manufacturing due to manufacturing problems of the low pressure system and the high friction of the powder binder inside the extruder based system. In Figure 6 the $\mathrm{B}-\mathrm{C}-\mathrm{U}$ is shown in detail. The binder particles are stored in a transparent hopper formed box above the stop gear. The stop gear is driven by a stepper motor and controlled by a CNC-based software system. The distance between stop gear and wall is adjustable with the slide bar. To reduce test parameters the distance was fixed to $0.2 \mathrm{~mm}$. The incoming air hits the stop gear and separates the binder from the gear tooth. To assist this separating process and to prevent an agglomeration of the binder material in the binder storage, a vibration generator (air vibrator) is mounted to the Binder-Conveying-Unit. The mixed air and binder are transported with the air flow to the roving (application on the roving).

The binder output is one major quality factor for a constant quality of binder rovings. For a homogeneous binder output different parameters within the B-C-U were varied and the corresponding binder output was measured. Three parameters (stop gear rotation, air flow, and vibration frequency) were analyzed. The results are shown in Figure 7 to Figure 9. The binder output was measured with an electronic balance XP10002S from METTLER TOLEDO, USA. The first figure (Figure 7) shows the dependence of five different gear rotations. All five output trends correlate linearly to the process time. The maximum

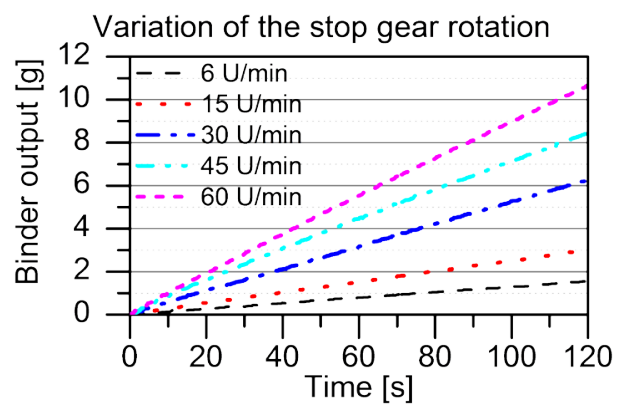

Figure 7: Parameter variation for the binder application unit.

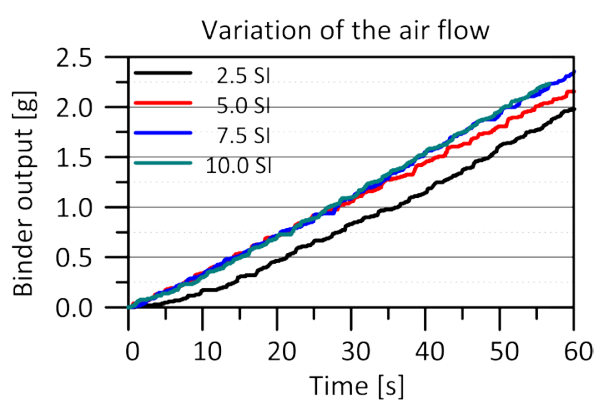

Figure 8: Parameter variation of the air flow.

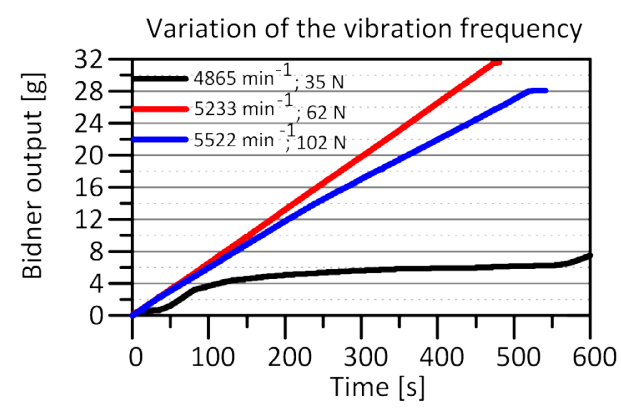

Figure 9: Parameter variation of the vibration frequency.

output is optimized for the above listed parameters. If a further binder output is requested, for example for more than one tape, a wider stop gear or a larger distance between stop gear and wall (actual $0.2 \mathrm{~mm}$ ) is necessary. Figure 8 shows the dependence of four different values ( 2.5 to 10 standard liters - $\mathrm{Sl}$ ) for the incoming air flow. After linear fitting the $5 \mathrm{Sl}$ variant shows the best standard deviation. As last parameter the air vibrator frequency can be changed. Different input pressures result in different frequencies, which also results in different working forces. The results are compared to each other in Figure 9. With 


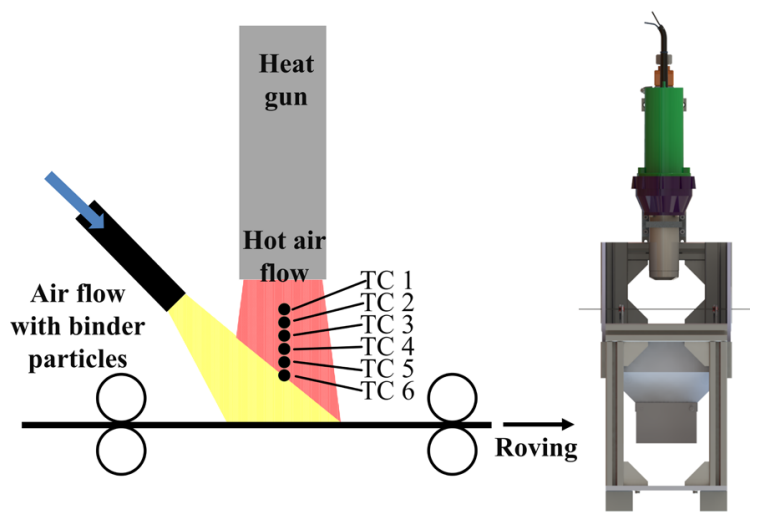

Figure 10: Schematic positioning of the binder heat-up system.

the lowest frequency (black curve with 4865 min-1 and $35 \mathrm{~N}$ ) the binder material agglomerates and the output is inhomogeneous. In contrast to this, the maximum frequency (blue curve with 5522 min-1 and $102 \mathrm{~N}$ ) shows two different gradients. The parameters with a frequency of 5233 min-1 and a working force of $62 \mathrm{~N}$ show a consistent binder output.

As result of this parameter study the final process parameters for the Binder-Conveying-Unit were determined:

- Air flow: $5.0 \mathrm{Sl}$

- Vibrator parameters: $5233 \mathrm{~min}-1$ (frequency), $62 \mathrm{~N}$ (working force)

- Gear rotation: in dependence of the achievable binder content

After the binder material is consistently distributed inside the air flow the material needs to be heated up to fix the particles on the roving. Inside the $\mathrm{B}-\mathrm{A}-\mathrm{U}$ (Figure 10 right) the binder material is heated up with an electronic heat gun (TRIAC S from Leister, Switzerland). The temperature of the heat gun varies between room temperature and $700^{\circ} \mathrm{C}$. The deployed heat gun has ten different power adjustments to vary the temperature. The binder material was supported separately inside the hot air stream with an angle of $45^{\circ}$. Six thermocouples were placed inside the hot air flow to measure the temperature distribution.

The main process parameter of the binder application unit (Figure 5) is the coating of carbon fibers with binder particles inside a hot air flow. Temperature distributions for different heat gun adjustments are shown in Figure 11. The positioning of

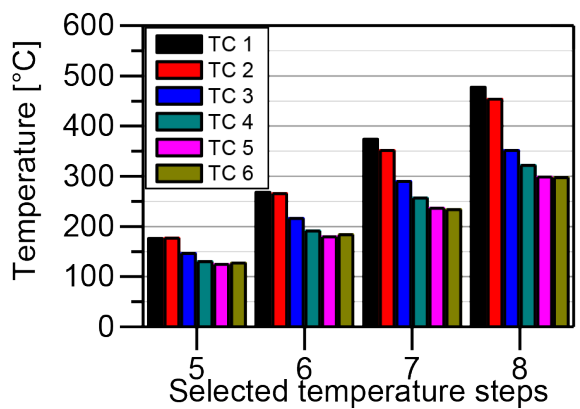

Figure 11: Temperature distribution of the heat gun.

the thermo couples is shown in Figure 10. The distance between the heat gun and TC 1 is $1.5 \mathrm{~cm}$ and between each couple (TC 1 to TC 6) is $1 \mathrm{~cm}$.

Depending on the temperature distribution four different heat gun adjustments for a first test series were chosen. All parameters for the test are described below:

- Roving speed $5 \mathrm{~m} / \mathrm{min}$

- Stop gear rotation speed $2.5 \mathrm{~min}^{-1}$

- Vibration force $62.26 \mathrm{~N}$

- Vibration frequency $5232 \mathrm{~Hz}$

- Air flow $5 \mathrm{~S} 1$

- Binder type: XB 3366

For the first test a test piece (double-sides conductive adhesive pad for a scanning electron micrograph) was glued on a roving and transported through the B-T-R (Figure 5). The binder particle was sprayed onto the test piece within the B-A-U. SEM figures of the applied powder binder are shown in Figure. The first SEM figure (A) shows two binder particles at room temperature. The particle surfaces are rough and edged. Similar occurrence shows figure (B) with heat gun adjustment $5\left(\approx 110^{\circ} \mathrm{C}\right.$ roving temperature $)$. With further increasing of the temperature (setting 6 - figure C) first indications of melting are visible at some particles. Other particles are primarily identical to figure (B). With an even higher temperature (setting 7 - roving temperature $\approx 210^{\circ} \mathrm{C}$ - figure $\mathrm{D}$ ) all particles are melted and formed to their best energy-related geometry (spherical). With even higher temperatures (setting 8 - no figure) the polymer particles are compressed to flat particles, because of the air flow and the high temperature (low viscosity).

Depending on these test results, the optimal temperature for the binder application unit was fixed as follows. The temperature input should melt the particles on the surface to ensure an adhesion to the roving material. 


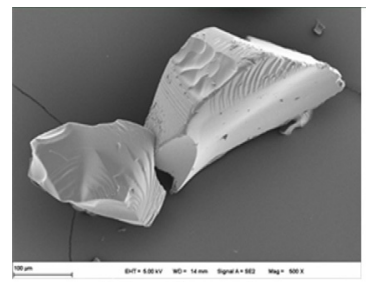

A) Room Temperature

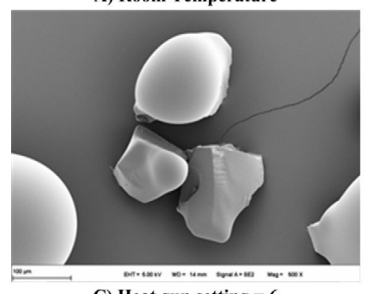

C) Heat gun setting $=6$

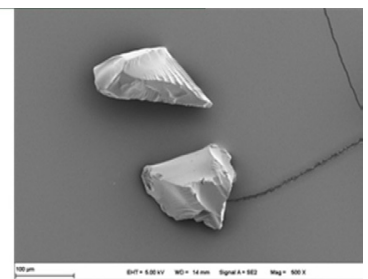

B) Heat gun setting $=5$

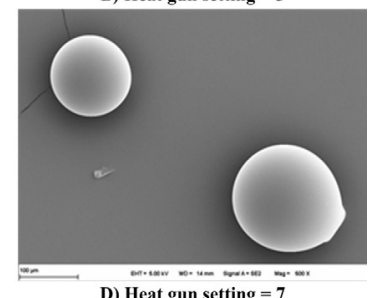

D) Heat gun setting $=7$

Figure 12: XB 3366 binder temperature analysis (SEM).

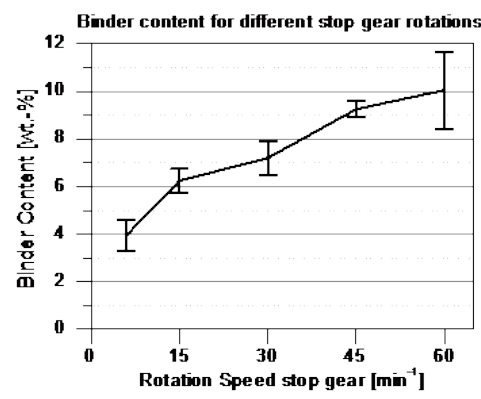

Figure 13: Achievable Binder Content.

Melting to the core is not meaningful, since the binder material infiltrate the roving and thus adhesion between different rovings could be difficult. At room temperature and with heat gun setting 5 the particles are solid in contrast to the particles with heat gun setting 7 . Because of the partial binder particle melting (only the surfaces) the best setting for the heat gun is between setting 6 and 7.

For the first binder manufacturing test series different binder rovings with up to 10 mass- $\%$ of binder were produced. In Figure 13 the plot of the "Binder Conveying Velocity" and the "Binder Content" is shown. A degressive behavior of the binder content and the binder conveying velocity is visible. With modifications of binder conveying unit (especially the distance from the slide bar to the stop gear wheel) or with a lower roving velocity inside the binder application unit the binder content could be increased. The binder content for available binder rovings are from 2.25 to nearly 8 weight $\%$ and depends on the

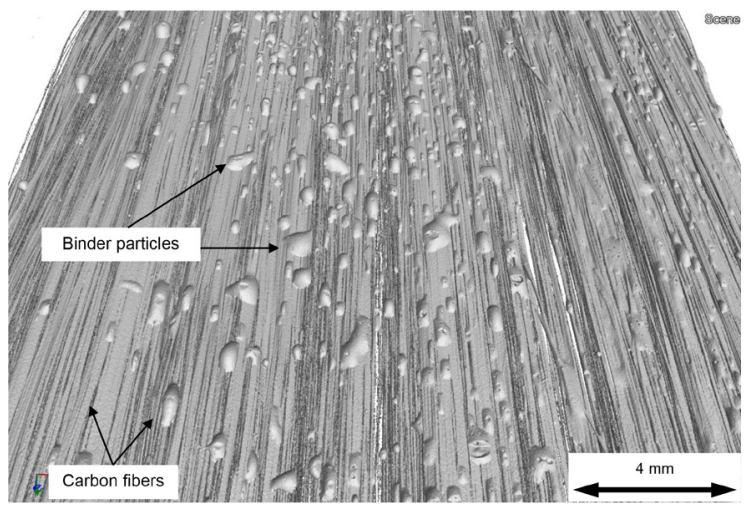

Figure 14: Roving with binder particles on the surface (Computer tomography).

supplier. The whole range is covered by the new Binder-Application-Unit.

With the newly developed binder application a homogeneous binder content could be applied in an air stream and on a spread carbon fiber roving. In Figure 14 a roving with binder particles is shown.

The binder particles are homogeneously distributed on the surface of the roving.

\section{Conclusions}

A new manufacturing method for binder rovings was developed and investigated to compensate the disadvantages of the state of the art processes. For that purpose a new manufacturing test rig for the binder application was designed. The main focus of this paper was on the binder conveying unit. Within the conveying unit a predefined binder material is supported into an air stream. Different system parameters were varied correlated to the binder output to enable a reproducible production quality. With an air stream the binder particles were transported to the next unit, in which the binder particles are heated up for the fixation on the roving. As heating system for the polymer binder particles a hot air stream (electric air heater) is installed. The hot air melts or changes the material phase of the binder before the particles are sprayed on a spread roving. It was shown, that a homogeneous binder output is possible with the developed conveying unit. Thus, the application as in-line binder application system in a mass production preforming concept is possible (In-Situ Dry Fiber Placement). 
For this target further research is required. The next research step is the manufacturing of preforms from the produced binder rovings. Different analysis with this preforms for example the measurement of the storage modulus, the permeability of the dry preform or the material behavior of an infused preform are then possible. The main question of these tests is the mechanical dependence of the dry and infused preforms depending on the binder content.

\section{Acknowledgements}

The research project was financially supported by the "Stiftung Rheinland-Pfalz für Innovation" within the project "Entwicklung eines Online-Bebinderungs- und Ablegeverfahrens zur automatisierten Herstellung lastoptimierter Preforms".

\section{References}

1. M. Neitzel, P. Mitschang, and U. Breuer, Handbuch Verbundwerkstoffe: Werkstoffe, Verarbeitung, Anwendung, ed., vol. 2, M. Neitzel, P. Mitschang, and U. Breuer, Auflage, München: Hanser, 2014.

2. C. Weimer, Zur nähtechnischen Konfektion von textilen Verstärkungsstrukturen für FaserKunststoff-Verbunde, IVW Schriftenreihe, ed. M. Neitzel, Kaiserslautern: IVW GmbH, Kaiserslautern, 2002.

3. A. Spickenheuer, M. Schulz, K. Gliesche, and G. Heinrich, "Using tailored fibre placement technology for stress adapted design of composite structures," Plastics Rubber and Composites, vol. 37(5-6), pp. 227-232, 2008.

4. P. Mattheij, K. Gliesche, and D. Feltin, "3D reinforced stitched carbon/epoxy laminates made by tailored fibre placement," Composites Part A: Applied Science and Manufacturing, vol. 31(6), pp. 571-581, 2000.

5. P. Crothers, K. Drechsler, D. Feltin, I. Herszberg, and T. Kruckenberg, "Tailored fibre placement to minimise stress concentrations," Composites Part A: Applied Science and Manufacturing, vol. 28(7), pp. 619-625, 1997.

6. A. Spickenheuer, K. Uhli, K. Gliesche, H. Heinrich, A. Albers, and N. Majic, "Steifigkeitsoptimierung von Faserverbund- bauteilen für den extremen Leichtbau," in 12. Chemnitzer Textiltechnik-Tagung, Chemnitz, Germany, 2009.

7. C. Weimer, T. Preller, P. Mitschang, and K. Drechsler, "Approach to net-shape preforming using textile technologies. Part II: holes," Composites Part A: Applied Science and Manufacturing, vol. 31(11), pp. 1269-1277, 2000.

8. F. Michl and M. Coquel, "Fully-automated production of complex CFRP parts using FibrePatch-Preforming technology," JEC-Composites, vol. 87, pp. 108 - 110, 2014.

9. O. Meyer, "Fiber Patch Preforming," in Bayern Innovation, Cluster Treff. München, 2008.

10. K. Drechsler, "Automatisierte textile Vorformlingtechnologie - Automated textile Preforming Technologies," in Bayern Innovativ Cluster Treff, München, 2011.

11. K. Gliesche and D. Feltin, Preforming und Tailored Fibre Placement, Ausgsburg: Carbon Composite, 1999.

12. M. Belhaj et al., "Dry fiber automated placement of carbon fibrous preforms," Composites Part B: Engineering, vol. 50, pp. 107-111, 2013.

13. A. Mills, Z. Patel, G. Dell'Anno, and M. Frost, "Resin transfer moulding: Novel fabrics and tow placement techniques in highly loaded carbon fibre composite aircraft spars," Sampe Journal, vol. 43(3), pp. 67-72, 2007.

14. J. Kraus, "Bauteilgerechtes 3D-Preforming für die Serie," in Maschinenmarkt, 2012.

15. Toho Tenax preform technology wins AVK conference award. (2013, Sept. 9). [Online]. Available: http://www.composites world.com/ news/toho-tenax-preform-technology-wins-avkconference-award

16. Strukturbauteile mal anders. (2014, July 7). [Online]. Available: http://www.k-zeitung.de/ strukturbauteile-mal-anders/150/1086/78525/

17. M. Schneider, "Carbon Fiber Materials for Automated Processes," in Toho Tenax Symposium Carbon Composite Innovations 2011, 2011.

18. A. Geßler, "The Industrialization of Advanced Composites through Textile Technology," in SAMPE Swiss / Technical Conference, ETH Zürich: SAMPE, 2011. 